e-ISSN: 2359-5078

\title{
Competitividade brasileira no comércio exterior da carne bovina
}

Brazilian competitiveness in the foreign trade of the Beef

\author{
Jessica Maria Vicensotti ${ }^{1}$, Adriana Estela Sanjuan Montebello ${ }^{2}$, Marta Cristina Marjotta-Maistro ${ }^{3 *}$
}

\author{
${ }^{1 *}$ Universidade Federal de São Carlos - Graduanda do Curso de Engenharia Agronômica - Centro de Ciências Agrária (CCA). Rod. Anhanguera, km 174, CP 153 - 13600- \\ 970 - Araras, SP - Brasil. < marjotta@ufscar.br> \\ ${ }^{1,3}$ Universidade Federal de São Carlos - Docente do Departamento de Tecnologia Agroindustrial e Socioeconomia Rural (DTAiSeR/CCA) - Rod. Anhanguera, km 174, CP \\ 153 - 13600-970 - Araras, SP - Brasil
}

\section{Resumo}

O trabalho teve como finalidade verificar a competitividade da carne bovina brasileira no cenário internacional e identificar quais eram os fatores que a afetaram no período ente 1994 a 2015. Para isso, o trabalho foi dividido em quatro objetivos específicos, sendo estes: estudar a cadeia produtiva da carne bovina brasileira e seu desempenho no mercado internacional, identificando as principais barreiras ao comércio internacional deste produto; calcular os indicadores de competitividade, sendo Coeficiente de Exportação, market share e Índice de Vantagem Comparativa Revelada. Os resultados alcançados mostram que o Brasil tem superado algumas fraquezas e se encontra numa posição favorável em relação ao comércio internacional de carne bovina.

Palavras-chave: bovinocultura, comercialização, market share

\begin{abstract}
The study aimed to verify the competitiveness of Brazilian beef in the international scenario and to identify the factors that affect it in the period between 1994 and 2015. For this, the work was divided in four specific objectives, these being: to study the chain Production of Brazilian beef and its performance in the international market, identifying the main barriers to international trade in this product; to calculate Competitiveness indicators, such as Export Coefficient, market share and Revealed Comparative Advantage Index. The results show that Brazil has overcome some weaknesses and is in a favorable position in relation to the international beef trade.
\end{abstract}

Keywords: cattle sector, commercialization, market share

\section{Introdução}

De acordo com Silva et. al (2013), a partir dos anos 1990, o Brasil se inseriu com competitividade no comércio internacional de carne bovina e intensificou sua capacidade produtiva através do melhoramento de infraestrutura e criação de animais, acarretando um número expressivo no crescimento de cabeças de gado. Segundo o autor, o Brasil é beneficiado pela ampla extensão territorial e por fontes alimentícias apropriadas para a criação de gado, facilitando sua expansão ao longo dos anos. Desta forma, é caracterizado autossuficiente para atender a demanda interna e manter relações comerciais com outros países, através da exportação. Além disso, de acordo com Zucchi e Caixeta Filho (2010), entre os diferenciais competitivos que o Brasil possui frente aos seus principais países concorrentes, destacamse: a grande extensão de terras, que permitem ganho em escala e expansão da atividade pecuária; a genética bovina melhorada e adaptada ao meio ambiente; a tecnologia necessária para aumentar os índices de produtividade e, principalmente, as condições climáticas favoráveis à produção pecuária de baixo custo e ambientalmente correta.

Segundo Furquim e Cyrillo (2012), a carne bovina tem destaque no agronegócio brasileiro, com elevada participação no Produto Interno Bruto [PIB] e nas exportações do agronegócio, além de ser um alimento de comprovada importância nutricional. A carne bovina in natura apresentou valor de US\$ 339,36 milhões em exportações no mês de março de 2015, de acordo com dados do Ministério do Desenvolvimento Indústria e Comércio Exterior [MDIC] (MDIC, 2014). Segundo dados do Ministério da Agricultura Pecuária e Abastecimento [MAPA] (MAPA, 2015), o Brasil lidera o ranking de maior exportador de carne bovina do mundo desde 2008 e as estatísticas mostram crescimento ao longo dos anos. De acordo com dados do MDIC (2015), o valor das exportações totalizou US $\$ 4.006 .139 .123$ e, em 2014, esse valor foi de US\$ 5.794.260.374, representado crescimento de 44,63\%. Portanto, este segmento também contribuiu como importante fonte de geração de divisas para o país. 
Zucchi (2010) destacou também que do ponto de vista social, devido à sua complexa cadeia produtiva, a atividade é importante fonte geradora de milhares de empregos diretos (antes da porteira) e indiretos (depois da porteira, por exemplo: fornecedores de insumos, distribuição etc.).

Diante do exposto, o trabalho pretende tem como objetivo geral analisar a competitividade brasileira no mercado internacional de carne bovina no período de 1994 a 2015. Especificamente, este estudo buscou: i) apresentar a cadeia produtiva da carne bovina brasileira (mostrando quais são os seus segmentos); ii) mostrar o desempenho da carne bovina brasileira no mercado internacional; iii) identificar as principais barreiras ao comércio internacional deste produto; iv) e calcular os seguintes indicadores de competitividade: Índice de Vantagem Comparativa Revelada [IVCR], Coeficiente de Exportação [CE] e Market Share [MS], identificando a importância de cada um deles trabalho.

\section{Material e Métodos}

Foi utilizada a análise gráfica e tabular de dados secundários obtidos da pesquisa bibliográfica e da pesquisa quantitativa. Portanto, a pesquisa foi conduzida de duas formas: i) Pesquisa bibliográfica através de revisões bibliográficas, englobando trabalhos acadêmicos, sites especializados de setores públicos e privados, entre outras produções existentes na literatura. Estes trabalhos foram selecionados com base nos assuntos publicados sobre a temática levantada neste artigo; ii) a pesquisa quantitativa realizada através do levantamento de dados secundários. Estes dados foram obtidos através de fontes de dados oficiais de pesquisa sobre o tema em questão. Estes foram: a) Instituto Brasileiro de Geografia e Estatística [IBGE] que tem disponível dados estatísticos sobre o setor, divulgando mensalmente, indicadores de produção pecuária; b) MAPA que contribui com informações vinculadas ao setor agropecuário como valores de produção agropecuária, processamento, e distribuição de produtos de origem agropecuária; c) MDIC que contribui com informações vinculadas com o comércio exterior, como valores de importação e exportação de produtos; d) Food and Agriculture Organization of the United Nations [FAO] (FAO, 2016), que disponibiliza informações sobre variáveis de comércio internacional, conhecido pela sigla em inglês Faostat, trazendo dados de valor das exportações e importações bem como a quantidade exportada e importada de produtos da agropecuária por países.

Os principais indicadores de competitividade coeficiente de exportação, vantagem comparativa revelada e market share foram calculados para o período de 1994 a 2015 e da seguinte forma:

\section{Coeficiente de exportação}

O coeficiente de exportações foi calculado em relação ao valor da produção (Levy e Serra, 2002). Segundo Fonseca et al. (2000), este coeficiente permite analisar a dependência do setor dos mercados doméstico e externo. Assim, quanto maior o coeficiente maior a dependência do setor no mercado externo e, consequentemente, maior vulnerabilidade deste a choques internos. De acordo com Haguenauer (1998), o coeficiente de exportação das unidades de maior porte é, em geral, muito superior ao das pequenas e microempresas o que pode ser exemplificado pelo setor de abate de aves, no qual existem inúmeras pequenas unidades que atendem exclusivamente a mercados regionais, e calculado segundo a equação 1 :

$$
\mathrm{CE}_{\mathrm{t}}^{\mathrm{i}}=\frac{\mathrm{X}_{\mathrm{t}}^{\mathrm{i}}}{\mathrm{VP}_{\mathrm{t}}^{\mathrm{i}}} \times 100
$$

onde, CE: é o coeficiente de exportações da atividade i no período t; X: é o valor das exportações da atividade i no período t; VP: é o valor bruto da produção da atividade i no período $t$.

Os dados das exportações de carne bovina utilizados no cálculo do coeficiente foram retirados do banco de dados da FAO (FAO, 2016). Os dados de valor bruto da produção foram obtidos junto ao banco de dados de Pesquisa Trimestral do Abate de Animais do IBGE (IBGE, 2015). Segundo o MAPA (2015), o Valor Bruto da Produção Agropecuária [VBP] corresponde ao faturamento bruto dentro do estabelecimento e foi calculado com base na produção da safra agrícola e da pecuária, e nos preços recebidos pelos produtores nas maiores praças do país, o valor real da produção, descontada a inflação foi obtido pelo índice Geral de Preços- Disponibilidade Interna [IGP-DI] (IPEADATA, 2015).

\section{Market share}

De acordo com Hermida e Xavier (2012), o indicador de market share setorial expressa à proporção das exportações do grupo setorial “i” pelo país “j” relativamente às exportações mundiais totais do grupo setorial" i", para medir a parcela de mercado do setor selecionado, obtida pelo Brasil do total exportado mundialmente, sendo expresso através da equação 2 :

$$
\mathrm{MS}=\frac{\mathrm{X}_{\mathrm{ij}}}{\mathrm{X}_{\mathrm{i}}} \times 100
$$

onde, $\mathrm{X}_{\mathrm{ij}}$ : é o valor das exportações do grupo setorial "i” pelo país “j”; $X_{i}$ : é o valor das exportações do grupo setorial " $i$ " do mundo. 
Segundo Figueiredo, Santos, Lírio (2005), os trabalhos baseados em modelos de market share visam avaliar a participação de um país ou região no fluxo mundial ou regional de comércio e desagregar as tendências de crescimento das exportações e, ou, importações de acordo com seus determinantes.

Os dados das exportações brasileiras de carne bovina, assim como os das exportações mundiais de carne bovina utilizados no cálculo do índice foram obtidos do banco de dados da FAO (FAO, 2016).

\section{Vantagem Comparativa}

Originalmente, este indicador foi desenvolvido por Balassa (1965), baseado no conceito de Vantagem Comparativa Revelada [VCR]. Conforme Hermida e Xavier (2012), este indicador permite captar se determinado país possui ou não vantagens comparativas em certo setor, com base na participação deste país nas exportações mundiais totais. Os autores explicaram que os estudos sobre os determinantes da competitividade internacional originam-se no modelo ricardiano clássico, que fornece a explicação teórica básica para o comércio internacional por meio do chamado "Princípio das Vantagens Comparativas". Este modelo sugere que cada país deve especializar-se na produção daquela mercadoria em que é relativamente mais eficiente, ou que tenha custo relativamente menor, que será, portanto, a mercadoria a ser exportada. A fórmula do VCR pode ser expressa através da equação 3 (Balassa, 1965):

$$
\operatorname{VCR}=\frac{\left(\frac{X_{i j}}{X_{j}}\right)}{\left(\frac{X_{i}}{X}\right)}
$$

onde, $\mathrm{X}_{\mathrm{ij}}$ : é o valor das exportações do grupo setorial “i” pelo país “j”; $\mathrm{X}_{\mathrm{i}}$ : é o valor das exportações do grupo setorial “i” do mundo; $\mathrm{X}$ : é o valor das exportações totais realizadas pelo país “j”; X: é o valor total das exportações mundiais totais.

Se o VCR é maior que a unidade (VCR >1), o país "j" possui vantagens comparativas no grupo setorial “i” em relação à economia mundial, demonstrando que este país possui um market share neste grupo setorial superior à sua participação no mercado mundial de todos os outros produtos. Kanadani et al. (2007) completou a análise e explicou que ocorrendo o contrário, quando VCR $<1$, significa que a região apresenta desvantagem comparativa na produção e exportação do referido produto i. Sendo VCR = 1, a região j não terá vantagem nem desvantagem na produção do produto i: a produção local supre as necessidades internas de consumo, não havendo excedente para ser exportado. Em outras palavras, se o valor do VCR, ao longo dos anos, for positivo, o país apresentará vantagem comparativa da exportação do produto analisado; caso contrário, VCR negativo demonstra desvantagem comparativa.

Os dados das exportações brasileiras e mundiais de carne bovina, e das exportações totais brasileiras e mundiais utilizados no cálculo do índice foram retirados junto ao banco de dados da FAO (FAO, 2016).

\section{Resultados e Discussão}

\section{Complexo agroindustrial da carne bovina e seus principais agentes}

Segundo Tirado et al. (2008), a cadeia da carne bovina é classificada como sendo completa, ou seja, todos os seus elos estão presentes indicando que a cadeia possui um grau alto de maturidade e o negócio está plenamente desenvolvido. $\mathrm{O}$ autor considera que, nesse aspecto, a cadeia produtiva da carne bovina brasileira é uma das mais complexas quanto à estrutura e aos agentes envolvidos.

Segundo Zucchi (2010), a cadeia de produção da carne bovina engloba atividades antes da porteira, sendo essas relacionadas aos suprimentos de insumos antes da fazenda; durante a porteira, que se refere ao abate e processamento, incluindo a distribuição; e, por fim, depois, ao atendimento ao consumidor final (nacional e porteira internacional), além das atividades de apoio como os institutos de pesquisa.

Assim, entre os integrantes da cadeia produtiva da carne bovina que propulsionam o progresso tecnológico, podem-se incluir a indústria produtora de insumos e a indústria de máquinas e equipamentos, que, caracterizamse pela difusão de conteúdo tecnológico cada vez mais sofisticado, bem como pela crescente presença na oferta e prestação de serviços associados à venda de insumos e maquinário (Tirado et al., 2008)

Segundo Santos et al. (2015), os pequenos e médios pecuaristas ainda compram os insumos para a produção nas casas agropecuárias, e vendem seus animais em contratos spot, ou seja, contratos de longo prazo. Nestes tipos de contratos, um dos itens que têm relevância para a negociação do acordo são os volumes de compra que estão em negociação. Porém, pecuaristas maiores começam a trabalhar com contratos a termo de curto prazo e parcerias de longo prazo.

De acordo com dados da Associação Brasileira de Indústrias Exportadoras de Carnes [ABIEC] (ABIEC, 2016), em 2013, foram movimentados $\mathrm{R} \$ 40,24$ bilhões pelo setor de carne bovina no período antes da fazenda, ou seja, com insumos e serviços, sendo eles nutrição, protocolos e sêmen, sanidade animal, óleo diesel, insumos agrícolas, energia elétrica, manutenção, serviços e peças, funcionários e encargos, despesas administrativas, e reinvestimentos. 
No primeiro trimestre de 2014, foram abatidas 8,367 milhões de cabeças de bovinos, sendo este valor superior ao registrado no primeiro trimestre de 2013, em 2,9\% (IBGE, 2014). Em nível nacional, segundo o IBGE (2015), em 2014, os principais estados produtores de carne bovina considerando o número de abate de bovinos são Mato Grosso, Mato Grosso do Sul, Goiás, São Paulo e Minas Gerais.

Como forma de dar suporte a competitividade deste setor, em 2015, o Governo Federal tem direcionado muitos incentivos para a agroindústria através de financiamentos pelo Banco Nacional de Desenvolvimento Econômico e Social [BNDES] ou ainda com este tornando-se acionista (Santos et al., 2015). Os resultados desses incentivos têm sido alcançados, pois, desde 2008, o Brasil ocupou a primeira posição entre os exportadores de carne bovina mundiais (MAPA, 2014). Em 2014, foram exportados
US\$5.794.260.374 FOB, o equivalente a 2,57\% de participação no total das exportações brasileiras (MDIC, 2016).

De acordo com Santos (2014), são quatro as principais agroindústrias exportadoras de carne no Brasil, que juntas, totalizam um número de valor de ações igual a 1.337.372.670. A maior delas é a líder mundial no processamento de carne bovina, além de ovina e de aves, atuando em 340 unidades de produção comercializando com mais de 150 países. Não somente a empresa líder mas, todas as empresas maiores estão sob o Sistema de Inspeção Federal [SIF]. É esta inspeção que habilita as plantas para exportação (Santos et al., 2015). A Figura 1 mostra as plantas frigoríficas encontradas no Brasil cadastradas pelo SIF que, segundo Santos (2015), são habilitadas para exportação, totalizando 83 plantas.

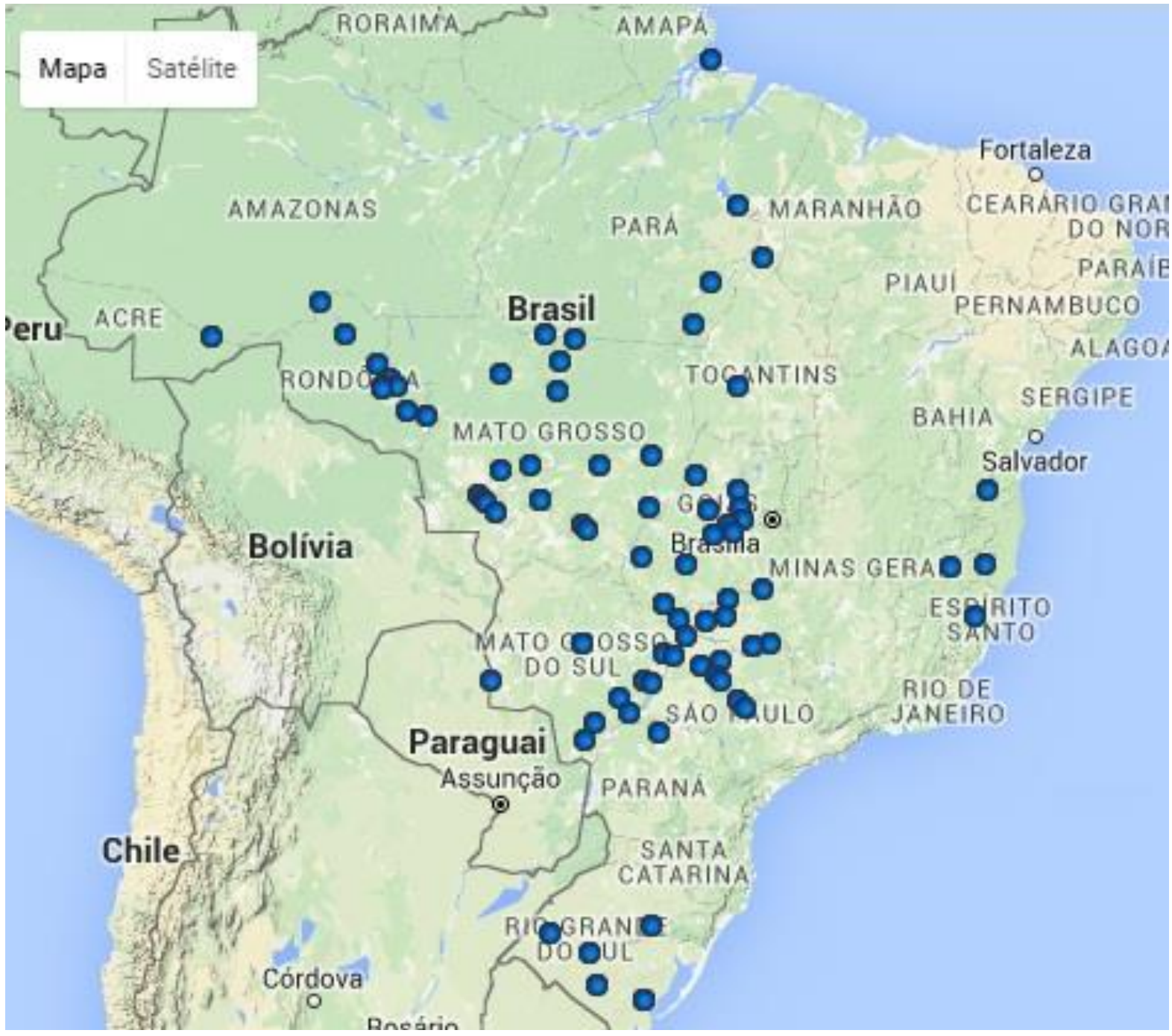

Figura 1. Distribuição das Plantas Frigoríficas nos Estados Brasileiros Fonte: ABIEC (2015) 
A maior parte das plantas frigoríficas instaladas estão localizadas nos estados de Mato Grosso, São Paulo e Goiás (Figura 1). As quatro principais empresas do setor possuem capital aberto, e em 2013 responderam por cerca de $45,8 \%$ do total de bois abatidos, num total de 90 unidades abatedoras. Os frigoríficos menores, sob o Sistema de Inspeção Estadual [SIE] e sob o Sistema de Inspeção Municipal [SIM], são voltados exclusivamente para o mercado interno (Santos et al., 2015).

Segundo Macedo e Lima (2011), a indústria frigorífica da carne bovina é um setor que apresenta uma competição global intensa demandando dos frigoríficos brasileiros significativos investimentos na expansão da sua capacidade, acarretando processos de fusões e aquisições. Tais investimentos, portanto, requerem recursos de longo prazo que dificilmente podem ser cobertos pelo autofinanciamento da indústria e, portanto, captar estes recursos em fontes de terceiros se faz necessário. Além disso, tais investimentos estratégicos viabilizados em grande parte por estes recursos causaram um considerável impacto na competitividade da cadeia produtiva de carne bovina, no Brasil e no mundo. Segundo os autores supracitados, as empresas globais brasileiras, através dos investimentos estratégicos, aumentaram a escala das operações, aprofundando a concentração e a centralização do capital na indústria da carne e derivados, visando aumentar sua liderança no mercado global. Desta forma, a concentração em grandes empresas nacionais trouxe benefícios à cadeia produtiva em relação ao mercado internacional, aumentando a competitividade da carne bovina brasileira e também buscando garantir segurança e qualidade.

\section{Desempenho da carne bovina brasileira no cenário internacional}

Em relação ao comércio exterior, de acordo com o Centro de Estudos Avançados em Economia Aplicada [CEPEA] (CEPEA, 2016), em 2015, o volume total de carne bovina in natura exportado totalizou 1,08 milhão de toneladas, somando um valor de US\$ 4,7 bilhões, porém um valor $19,5 \%$ menor que o observado em 2014, em decorrência da crise do petróleo em mercados compradores tradicionais como Rússia, Venezuela, e, em parte também da redução da oferta interna. Apesar disso, segundo dados do MAPA (2015), o Brasil lidera o ranking de maior exportador de carne bovina do mundo desde 2008, com o PIB se mostrando expressivamente crescente nos últimos três anos, totalizando um valor de 188 milhões no ano de 2015, valor muito superior a 158 milhões, observado em 2013 (CEPEA, 2015).

A relevância das exportações de carne bovina pode ser avaliada pela participação da exportação no total produzido no país (Calleman e Cunha, 2011). O crescimento das exportações e da produção nacional de carne foi apresentado na Tabela 1, bem como a

Tabela 1. Produção e exportação de carne bovina no Brasil de 2005 a 2015

\begin{tabular}{lrrr}
\hline Ano & Produção & \multicolumn{1}{c}{ Exportação } & \multicolumn{2}{c}{ Participação } \\
\hline & ---- 1000 t equivalente carcaça ---- & ---- $\%$ & ---- \\
2005 & 56.115 & 7.364 & 13,1 \\
2006 & 57.671 & 7.586 & 13,1 \\
2007 & 58.593 & 7.630 & 13,0 \\
2008 & 58.637 & 7.594 & 12,9 \\
2009 & 58.155 & 7.433 & 12,7 \\
2010 & 58515 & 7.794 & 13,3 \\
2011 & 58.160 & 8.072 & 13,8 \\
2012 & 58.527 & 8.138 & 13,9 \\
2013 & 59.467 & 9.126 & 15,3 \\
2014 & 59.746 & 9.990 & 16,7 \\
2015 & 58.443 & 9.601 & 16,4 \\
\hline
\end{tabular}

Fonte: MAPA (2015)

participação relativa das exportações no total produzido.

No período compreendido entre 2005 e 2015, no geral, a participação da exportação no total produzido foi crescente (Tabela 1). As exportações de carne bovina que representavam, 13\% do total produzido em 2005, representou 16,4\% em 2015, com exceção do período de 2008 a 2009, onde houve uma pequena queda que pode ser explicada pela ocorrência da crise financeira internacional de 2008, voltando a ser crescente a partir de 2010.

Segundo Melz et al. (2014), entre 2008 e 2011, houve queda nas exportações brasileiras de carne bovina, como reflexo da crise mundial iniciada no setor imobiliário dos Estados Unidos. Contudo, enquanto as exportações mundiais cresceram 47\%, as brasileiras cresceram 568\%, entre 1995 e 2012, revelando sua competitividade. Isso porque no Brasil, a criação é extensiva, não utilizando proteína animal na sua alimentação, reduzindo o risco da Encefalia Espongiforme Bovina [EEB].

Além disso, Marfrig Group (2008), coloca que o Brasil manteve posição de liderança nas exportações mundiais com 24,9\% no total em 2008, mesmo diante da significativa diminuição verificada no comércio com a União Europeia, um dos principais destinos de exportação em 2007 e 2008, a partir de fevereiro de 2008, em decorrência das restrições impostas pelo bloco europeu em relação ao número de fazendas brasileiras autorizadas a fornecer animais para exportação. 
Segundo o relatório anual da ABIEC (2015), os principais importadores de carne bovina brasileira in natura, em 2015, foram respectivamente Hong Kong, Egito, Rússia, Venezuela, China, Iran, Chile, Itália, Holanda e Argélia. Os dados de importação - valor e quantidade- por país importador estão apresentados na Tabela 2.

Tabela 2. Principais países importadores da carne bovina in natura brasileira em 2015

\begin{tabular}{lrr}
\hline \multicolumn{1}{c}{ País } & \multicolumn{1}{c}{ Valor } & \multicolumn{1}{c}{ Quantidade } \\
\hline & ----1000 US\$ --- & ------- t -------- \\
Hong Kong & 657.296 & 165.517 \\
Egito & 624.309 & 178.008 \\
Rússia & 551.872 & 169.457 \\
Venezuela & 534.044 & 93.269 \\
China & 476.246 & 97.450 \\
Iran & 381.436 & 97.469 \\
Chile & 256.099 & 54.165 \\
Itália & 196.298 & 29.138 \\
Holanda & 137.482 & 15.758 \\
Argélia & 84.933 & 19.789 \\
\hline Fonte: ABIEC (2015) & &
\end{tabular}

De acordo com a Tabela 2 verificou que Hong Kong, apesar de ser a maior compradora em termos de valores, fica em terceiro lugar em termos de quantidade importada, sendo que o país que ocupa a primeira posição é o Egito, seguido da Rússia. Tal fato pode ser explicado pela variação no valor cobrado pela tonelada de carne bovina in natura, sendo que para Hong Kong, o valor foi maior que para Rússia e Egito.

Para a carne industrializada e processada, os Estados Unidos lideraram o ranking de maior exportador, seguido pelo Reino Unido, Bélgica, Itália e Suécia (Tabela 3). Outro ponto importante foi que de um total de 102 países listados no relatório anual da ABIEC (2015), apenas cinco foram responsáveis por mais da metade das importações e consumo de carne bovina brasileira in natura, são eles: Hong Kong (14\%), Egito (13\%), Rússia $(12 \%)$, Venezuela $(11 \%)$ e China $(10 \%)$.

No decorrer de 10 anos, de 2005 a 2015, houve uma mudança significativa em relação aos principais compradores da carne brasileira, sendo que em 2005, a Rússia liderava as importações de carne bovina in natura brasileira seguida do Egito, Holanda, Reino Unido, Itália, Chile, Alemanha, Argélia, Bulgária e Arábia Saudita (Tabela 4). O fato de alguns destes países terem deixado de importar a carne in natura brasileira pode ser explicado pela influência de barreiras sanitárias que, segundo Waquil e Alwim (2015), influenciam os fluxos comerciais, em vista do recente surgimento de focos de EEB, popularmente conhecida como Mal da Vaca Louca, e de febre aftosa.
Outro ponto relevante foi o comportamento da China, que em 2015 teve sua importação de carne bovina crescente enquanto os demais países decresceram. A série histórica das importações de carne bovina in natura por país (em valores) está representada na Figura 2.

Tabela 3. Principais países importadores da carne bovina industrializada brasileira em 2015

\begin{tabular}{|c|c|c|}
\hline País & Valor & Quantidade \\
\hline & ---- 1000 US\$ ---- & ------- t ------- \\
\hline Estados Unidos & 282.708 & 30.063 \\
\hline Reino Unido & 126.842 & 25.019 \\
\hline Bélgica & 51.102 & 7.125 \\
\hline Itália & 26.385 & 3.278 \\
\hline Holanda & 24.014 & 4.504 \\
\hline Egito & 14.535 & 3.155 \\
\hline Porto Rico & 10.741 & 1.739 \\
\hline Jamaica & 10.336 & 2.411 \\
\hline Canadá & 8.665 & 1.720 \\
\hline Gambia & 6.238 & 3.054 \\
\hline
\end{tabular}

Fonte: ABIEC (2015)

Do total exportado em 2015, 86\% foi oriundo de carne in natura e $14 \%$ das carnes industrializadas. A evolução do valor das exportações da carne bovina, in natura de 2000 a 2015 (Figura 3), constatando-se que o saldo do comércio é crescente no período partindo de US\$ 503 milhões, em 2000, para US\$ 4 bilhões, em 2015.

A importância do setor nas exportações brasileiras foi confirmada também com a participação deste nas exportações totais brasileiras. Analisando uma série de 21 anos (de 1994 a 2015), notou que esta participação vem crescendo. Em 2000, a parcela de carne bovina no total das exportações brasileiras representou 1,4\%, enquanto que no ano de 2015 , o setor exportou US $\$ 5,4$ bilhões de um total de 191 bilhões exportados por todos os setores no Brasil, o que representou uma parcela de 2,8\%, o dobro do observado em 2000.

Além disso, a fim de se verificar a participação do Brasil no total das exportações de carne bovina no mundo, pode-se observar, de acordo com os dados da FAO (2013), que de 2000 a 2013, houve um crescimento significativo da participação da carne bovina brasileira nas exportações mundiais totais de carne bovina, de US $\$ 15,4$ bilhões exportados pelo setor de carne bovina por todo o mundo em 2000. O Brasil foi responsável por uma parcela de 5\% das exportações, enquanto que em 2013 de um total de US $\$ 40$ bilhões exportados, a parcela de 5,9 bilhões foi exportado pelo Brasil, concluindo que o Brasil foi responsável por aproximadamente 15\% das exportações de carne bovina do mundo. 


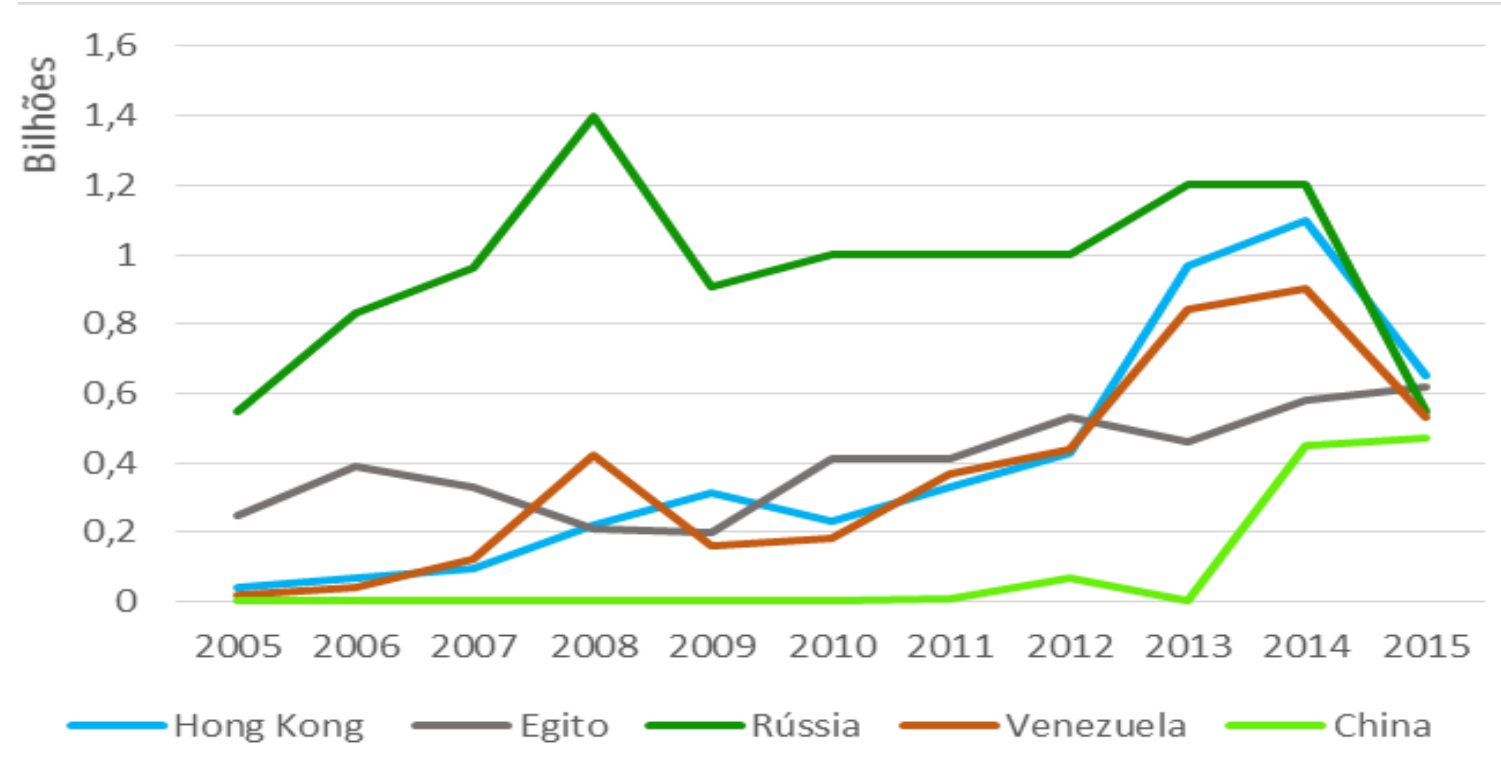

Figura 2. Série histórica, em US\$, de 2005 a 2015 da importação de carne bovina in natura brasileira por países Fonte: ABIEC (2015)

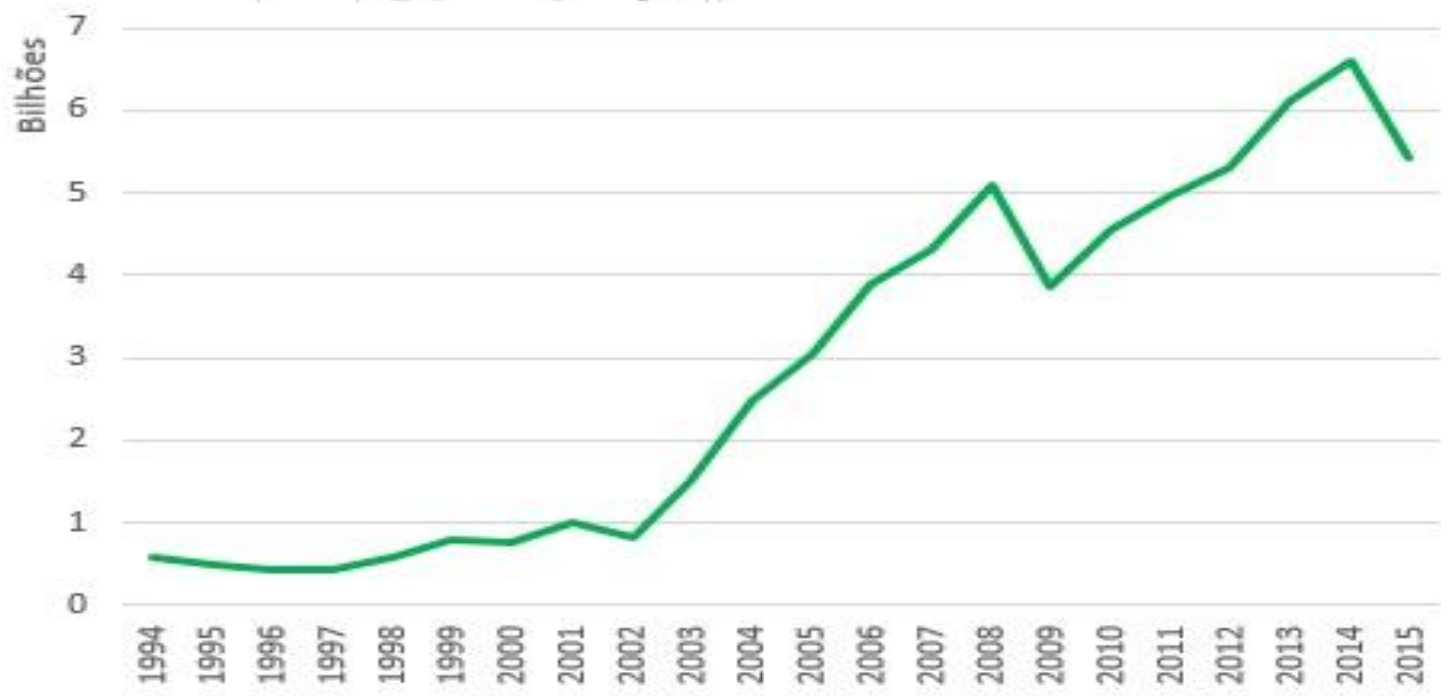

Figura 3. Evolução das exportações de carne bovina in natura e industrializada de 1994 a 2015

Fonte: adaptado de MDIC (2015)

Ademais, notou que apesar da crise econômica ocorrida em 2008, houve aumento nas exportações de carne bovina, passando de US $\$ 2,9$ bilhões exportados em 2005 para US\$ 4,9 bilhões em 2008, havendo apenas uma queda em 2009 voltando a se reestabelecer em 2010. Foi possível observar ainda, uma forte retração das exportações de carne bovina in natura em 2015 que somaram US\$ 4,6 bilhões comparados a 5,7 bilhões no ano anterior, 2014. Segundo ABIEC (2015), este recuo resultou de problemas conjunturais que afetaram negativamente alguns grandes mercados do Brasil, como Rússia, Hong Kong e Venezuela.

\section{Principais Barreiras Tarifárias e Não Tarifárias}

Embora a participação brasileira no mercado internacional seja expressiva, a carne brasileira ainda possui uma inserção no mercado internacional inferior ao potencial, e os preços recebidos pelo produto brasileiro ainda são considerados baixos. Entre os fatores que determinaram esta restrição de acesso ao produto 
brasileiro e menores preços, teve as elevadas barreiras tarifárias - tarifas e quotas tarifárias, e, a imposição de barreiras não-tarifárias - sanitárias e técnicas (Waquil e Alvim, 2006).

As barreiras tarifárias constituem-se em um imposto incidente sobre as importações efetuadas por um país e podem ser classificadas em específicas, ad valorem ou mistas. As específicas são fixas e cobradas por unidade do bem importado, as tarifas ad valorem são impostos cobrados como uma fração do valor dos bens importados (Schwantes, Campos e Líro, 2012).

Segundo Waquil e Alvim (2006), os países em desenvolvimento são os que impõem as maiores tarifas, a exemplo da China e do Brasil, neste caso, a Tarifa Externa Comum do MERCOSUL [TEC], que impõem tarifas de $25 \%$ e $11,5 \%$, respectivamente; no entanto, países ou blocos desenvolvidos como Estados Unidos da América [EUA], União Européia [EU], Rússia e Japão (importadores), em geral, não aplicam barreiras tarifárias sobre as importações de carne bovina, mas impõem outras medidas restritivas, como barreiras técnicas e sanitárias.

Segundo Rubin, Ilha e Waquil (2008), Hong Kong, principal importador da carne bovina in natura brasileira, não apresenta qualquer forma de barreiras ao setor brasileiro de carnes, semelhante a Rússia que apresenta um grau de imposição de barreiras bastante baixo ao setor de carnes quando comparados com os demais países, visto que as exigências sanitárias, principal barreira impeditiva utilizada pela maioria dos demais blocos e regiões, não são tão rigorosas, exceto a existência de proibições esporádicas quando há aparição de focos de febre aftosa.

As tarifas impostas pela China, conforme Rubin, Ilha e Waquil (2008), ao setor de carne vêm sendo reduzidas por conta de um acordo entre Brasil e o mercado chinês. A carne bovina (sem osso), que possuía uma tarifa de $39 \%$ ad valorem, chegaria até $12 \%$. A tarifa de $12 \%$ incidiu sobre os miúdos de bovinos até o ano de 2015, mas deverá ser eliminada entre quatro e sete anos.

De acordo com a ABIEC (2015), a carne brasileira in natura está sujeita à cota Hilton que é constituída de cortes especiais do quarto traseiro, de novilhos precoces, e seu preço no mercado internacional geralmente é mais alto do que o da carne em geral.

No setor agroalimentar, as regras formais podem ser determinantes para o processo de desenvolvimento econômico tanto no nível micro - da firma individual como no nível macro - de uma cadeia produtiva, de um estado ou de um país. No caso da carne bovina, as regras relacionadas ao controle sanitário desempenham especial importância, pois é a diferença entre os status sanitários dos países que acabam provocando o surgimento de barreiras ao comércio internacional deste produto (Miranda et al., 2004).
No que diz respeito às barreiras sanitárias e técnicas, classificam-se como impeditivas ou proibitivas, quando as barreiras sanitárias são tão rigorosas que acabam impedindo a entrada do produto, e, restritivas, quando as barreiras sanitárias acabam dificultando a entrada do produto (Rubin, Ilham e Silva, 2008).

Nos últimos anos, a partir da década de 1990, as crises sanitárias decorrentes dos casos de encefalopatia espongiforme bovina e influenza aviária (gripe aviária) reforçaram a importância do estabelecimento e cumprimento das regras sanitárias, e colocaram em dúvida a credibilidade daqueles países com menor capacidade de operacionalização ou demonstração de um sistema de defesa sanitário eficiente (Thome et al., 2010). O setor de carnes está sujeito as exigências de adequação técnica das embalagens e de questões sanitárias. No que se refere às questões sanitárias, podem ser citados como exemplos a proibição de importação pelos países da União Europeia da carne com osso, sob a alegação da existência de febre aftosa, e a sujeição das certificações de saúde animal e de saúde pública que devem ser expedidas pela autoridade oficial brasileira e aprovada pelo país importador, no caso da carne congelada. (Rubin, Ilha e Waquil, 2008).

A União Europeia reconhece o Princípio da Regionalização e permite, portanto, as importações de carne bovina in natura de regiões específicas de países que ainda têm áreas com vacinação de febre aftosa. Entretanto, o Bloco europeu restringe o livre comércio do produto através de um sistema de quota de importação e de outras exigências como a rastreabilidade bovina e a proibição do uso de hormônios na produção de carne. (Siqueira, 2016).

Por último, os subsídios à produção e à exportação são determinantes das maiores distorções nos preços internacionais. Exemplo disto, os EUA e a UE são responsáveis pelas maiores concessões de recursos para produção e exportação de carne bovina; em contrapartida, a maioria dos produtores dos países em desenvolvimento não dispõe de recursos subsidiados para produção ou exportação (Waquin e Alvim, 2015).

Segundo Silva, Triches e Malafaia (2011), o Brasil não tinha acesso aos mercados de países da América do Norte, especificamente os que compõem o Tratado Norte-Americano de Livre Comércio [Nafta], sobretudo pela adoção de rígidas medidas de caráter não tarifário, como aquelas voltadas à qualidade e sanidade do alimento, uma vez que estes países não reconhecem o acordo sobre a aplicação de medidas sanitárias da Organização Mundial do Comércio, que reconhece áreas livres de doenças dentro do País, conhecido como Princípio da Regionalização, assim, as exportações brasileiras de carne in natura estão proibidas, sob a alegação de ocorrência de contaminação por febre aftosa em alguns estados. 
Em 2014, segundo MAPA (2015), a Organização Mundial de Saúde Animal [OIE], reconheceu que os únicos estados brasileiros que compõem a zona não livre de febre aftosa são Amazonas, Roraima e Amapá, estando assim, o restante do país livre de febre aftosa e adequados às medidas de caráter sanitário para exportação.

Desta forma, segundo informações sobre Barreiras Técnicas ao Comércio do MDIC, regulamentos e padrões técnicos podem, muitas vezes, ser utilizados sem justificativa legítima para proteger os produtos nacionais contra produtos importados mais baratos e/ou de melhor qualidade, causando distorções ao comércio. O Acordo sobre Barreiras Técnicas ao Comércio (Acordo TBT da Organização Mundial do Comércio) visa, justamente, conter essa utilização indevida. Assim, o acordo TB'T (MDIC, 2019) determina que regulamentos técnicos, normas e procedimentos de avaliação da conformidade não devem criar obstáculos desnecessários ao comércio internacional, estabelecendo que regulamentos técnicos não devem ser mais restritivos ao comércio do que o necessário para atender a um objetivo legítimo, como proteção da saúde pública e do meio ambiente, considerando os riscos que o não cumprimento do objetivo poderia criar.

Análise da competitividade da cadeia de carne bovina brasileira em relação ao mundo através dos indicadores CE, MS e IVCR

Os resultados apresentados na Tabela 4 ilustram a competitividade da cadeia de carne bovina brasileira em relação aos demais países exportadores do mercado internacional através do cálculo dos indicadores.

De acordo com a Tabela 4 observa-se que o coeficiente de exportação (CE\%) apresentou valores crescentes de 2000 a 2006, havendo um decréscimo a partir de 2007, voltando a se recuperar em 2013. Se verificar os demais indicadores calculados para o período de 2000 a 2007 e 2007 a 2013, há comportamento semelhante (tendência de alta seguida de tendência de queda).

Segundo Sanguinet et al. (2013), entre 2000 e 2006 o Brasil apresentou um volume de carne exportada em evolução. Em dados mais precisos, de 2000 a 2006 o volume expandiu com crescimento de 77,26 \%. Em contrapartida, a partir de 2008, o volume decresceu em $46,76 \%$, até 2011 . Há nitidamente um crescimento seguido de uma involução.

Machado e Amin (2005) afirmaram que o rebanho bovino brasileiro cresceu muito no início da década de 2000 em resposta aos estímulos da demanda externa e que, por conta disso, a pecuária de corte vem sofrendo profundas transformações desde meados da década de noventa. A disponibilidade de terras a baixo custo permitiu expandir a produção, para atender a demanda mundial crescente pelo produto brasileiro. Isso traz ao Brasil vantagens perante concorrentes como Austrália e Estados Unidos que possuem elevados custos de produção em relação à atividade pecuária. O crescimento das exportações de carne exigiu que os frigoríficos se modernizassem, tendo em vista os rígidos padrões internacionais de controle de qualidade. A ocorrência da vaca louca, simultaneamente, em vários países da União Europeia e da febre aftosa na Argentina, em 2001, favoreceu o crescimento das exportações brasileiras de carne bovina. Assim, é possível observar um crescimento de 49,4\% no Coeficiente de Exportação no período de 2000 a 2015 calculado no presente trabalho.

Tabela 4. Coeficiente de Exportação [CE], Market Share [MS] e Índice de Vantagem Comparativa Revelada [IVCR] da carne Bovina Brasileira em relação ao mundo, 1994 a 2015

\begin{tabular}{|c|c|c|c|}
\hline Ano & $\mathrm{CE}$ & MS & IVCR \\
\hline \multicolumn{4}{|c|}{---------- \% ---------- } \\
\hline 1994 & nd & 3,45 & 3,38 \\
\hline 1995 & nd & 2,84 & 3,12 \\
\hline 1996 & nd & 3,02 & 3,38 \\
\hline 1997 & nd & 2,93 & 3,07 \\
\hline 1998 & nd & 4,21 & 4,50 \\
\hline 1999 & nd & 5,20 & 6,13 \\
\hline 2000 & 6,56 & 5,09 & 5,91 \\
\hline 2001 & 9,31 & 7,40 & 7,78 \\
\hline 2002 & 10,33 & 7,21 & 7,69 \\
\hline 2003 & 11,44 & 8,39 & 8,63 \\
\hline 2004 & 14,89 & 11,97 & 11,29 \\
\hline 2005 & 13,93 & 12,74 & 11,15 \\
\hline 2006 & 15,93 & 14,06 & 12,65 \\
\hline 2007 & 13,24 & 14,71 & 12,80 \\
\hline 2008 & 12,08 & 14,13 & 11,52 \\
\hline 2009 & 9,85 & 11,75 & 9,63 \\
\hline 2010 & 9,29 & 12,50 & 9,45 \\
\hline 2011 & 8,03 & 11,81 & 8,37 \\
\hline 2012 & 8,79 & 12,16 & 9,22 \\
\hline 2013 & 9,06 & 13,08 & 10,16 \\
\hline 2014 & 9,07 & nd & nd \\
\hline 2015 & 9,80 & nd & nd \\
\hline
\end{tabular}

Fonte: Cálculo do autor a partir dos dados da FAO (2013), MDIC (2015) e MAPA (2015)

Nota: Nd significa dados não disponíveis. No caso do CE, os dados do valor bruto da produção não estavam disponíveis de 1994 a 1999 e, portanto, impossibilitou o cálculo do CE neste período. No caso do MS e IVCR, os dados da FAO não apresentam informações atualizadas das variáveis de comercio exterior para os anos posteriores a 2013. 
Entretanto, segundo o MDIC, o volume brasileiro de carne bovina exportada apresentou sequência de queda entre 2007 e 2011. Neste período, o volume enviado aos diferentes países diminuiu $36,2 \%$ passando de 2.465 mil toneladas para 1.572 mil toneladas, fato que pode explicar o decréscimo observado no coeficiente de exportação. De acordo com informações da Scot Consultoria $(2010)^{1}$, entre os entraves que influenciaram diretamente o desempenho das exportações de carne pelo Brasil neste período 2007-2011 estão fatores como a maior produção nos Estados Unidos, em função do alto abate de fêmeas que, com frequência, vem retomando mercados; a desvalorização do real, reduzindo a competitividade do produto brasileiro e também a dependência de poucos mercados. A Consultoria também destacou que a partir de 2008, a concentração dos cinco maiores compradores da carne brasileira aumentou. Houve ainda uma redução de demanda de alguns importantes clientes, como a Europa, em função da crise financeira internacional. Todo este cenário certamente afetou os valores dos indicadores considerados neste trabalho.

Através do cálculo do market share também foi possível observar que o Brasil apresentou crescimento em sua participação no mercado mundial de carne bovina a partir dos anos 2000, que segundo Bushe et al. (2014), deu-se, principalmente, pela perda de mercado por parte da Argentina, que sofreu com a febre aftosa no começo da década de 2000. Especificamente, no Brasil, em 1999, houve mudança no regime cambial, acompanhado da desvalorização da moeda, o que também pode ter estimulado o aumento das exportações do país, o que ocasionou um maior valor do indicador de market share a partir deste período. Diante disso, observa-se que no período de 1994 a 2004 o MS aumentou de 3,45\% para $11,97 \%$, o que significa um aumento de $247 \%$, enquanto que no período de 2004 a 2013 o crescimento foi menor, de $11,97 \%$ passando para $13,08 \%$, representando um crescimento de apenas $9,27 \%$.

Pode-se observar, na Tabela 4, que os valores encontrados através do cálculo do IVCR foram maiores que 1, para todos os anos analisados, comprovando que o Brasil possui vantagem comparativa revelada para a carne bovina. Verifica-se que o produto apresentou, em média, valores crescentes de IVCR ao longo dos anos, o que, segundo Ilha e Souza (2005), significa que as exportações brasileiras vêm ganhando espaço no mercado internacional de carne bovina. Tal comportamento ocorre pelo fato desta commodity ter maior crescimento das exportações frente aos demais produtos exportados pelo Brasil relativamente ao crescimento das exportações mundiais.
Os resultados encontrados no período compreendido entre 1994 e 2002, foram muito semelhantes aos resultados encontrados por Ilha e Souza (2005) e por Waquil et al. (2006). De acordo com esses autores, o que contribuiu para que os países do Mercosul ampliassem a competitividade de sua exportação agrícola no mercado mundial foram: a abertura comercial, a estabilização econômica e o progresso tecnológico ocorridos na década de 1990. Outro aspecto que também favoreceu a expansão das exportações brasileiras foi, a partir de janeiro de 1999, o processo de desvalorização do real, tornando os produtos brasileiros mais competitivos no mercado internacional.

A partir do ano 2000, foi possível observar que o índice continuou crescente. O IVCR para 2000 era igual a 5,91 passando para 10,16 após 13 anos, um crescimento de $72 \%$, com ressalva para o ano de 2004 , que saltou de 8,62 , em 2003, para 11,29, havendo apenas uma queda em 2009, decorrente da crise econômica internacional de 2008 que diminui as exportações. Este crescimento pode ser explicado, segundo Fürstenau (2004), pelo grande salto que houve nas exportações brasileiras a partir de 2001. Esse aumento foi resultado da manutenção de um câmbio favorável às exportações, de uma política mais agressiva do governo na abertura de novos mercados para a carne brasileira, do certificado de zonas livres de aftosa sem vacinação e, por parte de outros estados da Região Centro-Oeste, em 2001, do certificado de zonas livres de aftosa com vacinação. Foi observado um crescimento de $234 \%$ do IVCR no período de dez anos compreendido entre 1994 e 2004, resultado bem diferente do observado no período seguinte, de 2004 a 2013, que apresentou decréscimo de 10\%.

\section{Conclusão}

O trabalho mostra que o Brasil consegue manter uma posição competitiva no comércio internacional de carne bovina diante dos seus principais concorrentes. A crescente participação do país no mercado internacional vem acompanhado por mudanças estruturais na indústria frigorífica nacional. Pela análise dos agentes participantes de sua cadeia produtiva, nota-se que esta posição de destaque foi conquistada pelo apoio de investimentos governamentais que influenciou na configuração do setor, o qual apresentase concentrado em poucas agroindústrias, com centralização dos abates em poucas plantas processadoras. Além disso, é possível verificar que o setor enfrenta alguns desafios fazendo com que os preços recebidos pelo produto brasileiro sejam considerados baixos. Dentre os fatores que determinam esta restrição de acesso ao produto brasileiro e menores preços, têm-se as barreiras, principalmente, a imposição de barreiras não-tarifárias (sanitárias e técnicas).

${ }^{1}$ Disponível em: http://g1.globo.com/mato-grosso/noticia/2012/03/queda-em-exportacoes-de-carne-ameaca-lideranca-mundial-pelo-brasil.html، Acesso em: 15 jun. 2016. 
Apesar disso, os indicadores CE e MS calculados no trabalho provam que, a partir do ano de 1994, o Brasil apresentou resultados positivos em relação à sua competitividade internacional, com destaque para o período compreendido entre 2000 e 2006, quando as exportações foram mais favorecidas, por conta do crescimento da demanda externa, principalmente devido à ocorrência da vaca louca em vários países da União Europeia e da febre aftosa na Argentina em 2001, favorecendo o crescimento das exportações brasileiras de carne bovina. Além disso, a mudança do regime cambial e desvalorização da moeda também favoreceram as exportações neste período, sendo observado assim, um aumento expressivo dos indicadores. O IVCR apresentou valores maiores que 1 e crescentes, indicando que a cadeia de carne bovina brasileira tem eficiência produtiva e comercial quando comparada aos outros países exportadores.

Assim, de modo geral, estes resultados demonstram o aumento da eficiência comercial do setor influenciado pelos esforços que o mesmo vem realizando para se tornar mais competitivo no cenário internacional.

\section{Referências}

Associação Brasileira das Indústrias Exportadoras de Carne Bovina [ABIEC]. 2016. Disponível em: <http://www. abiec.com.br/news_view.asp?id=\%7BBAD44981-36C04DE8-9B3A-58652839985C\%7D>. Acesso em 22 abr. 2016.

Balassa, B. 1965. Trade liberalization and "reveqaled" comparative advantage. The Manchester School, 3(2): 99123.

BRASIL. Ministério do Desenvolvimento, Indústria e Comércio Exterior. Secretaria de Comércio Exterior. 2009. ALICE-WEB: Sistema de Análise das Informações de Comércio Exterior via Internet. 1994-2015. Disponível em: $<$ http://aliceweb.desenvolvimento.gov.br>. Acesso em: 28 jun. 2009.

Centro de Estudos Avançados em Economia Aplicada Esalq USP [CEPEA]. 2016. Disponível em: <http://www.cepea. esalq.usp.br/>. Acesso em 04 jun. 2016.

Figueiredo, A; Santos, M.; Lírio, L.; V; S. 2005. Análise de market share e Fontes de Variação das Exportações Brasileiras de Soja. Revista de Economia e Agronegócio-REA, 2(3):335360, 2005.

Fonseca, R., Carvalho JR., M. e Pourchet, H. 1998. A orientação externa da indústria de transformação brasileira após a liberalização comercial. Funcex, Rio de Janeiro, RJ, Brasil.

Food and Agriculture Organization of the United Nations [FAO]. 2013. Disponível em: <http://www.fao.org/home/ en/>. Acesso em: 01 dez 2015.

Food and Agriculture Organization of the United Nations [FAO]. 2016. Disponível em: <fao.org>. Acesso em: 11 jul. 2016.

Franco, M. 2003. Desafios internos. Agroanalysis, São Paulo, 23(4): 16-20.
Furquim, N. R.; Cyrillo, D. C. 2012. Vantagens e desvantagens da pecuária no Brasil segundo atores da cadeia produtiva de carne bovina. Revista de Economia e Administração, 11(4): 482-505.

Ilha, A.daS.; Souza, M.J.P.de. 2005. Índices de Vantagem Comparativa Revelada e de Orientação Regional para alguns produtos do Agronegócio Brasileiro durante o período de 1992 a 2002. In: XLII Congresso Brasileiro da Sociedade Brasileira de Economia e Sociologia Rural, 2005, Ribeirão Preto. Disponível em: http://www.sober.org.br/ palestra/2/104.pdf. Acesso em: 01 mar. 2015.

Instituto de Pesquisa Econômica Aplicada [IPEADATA]. 2015. Instituto de Pesquisa Econômica Aplicada. Disponível em: http://www.ipeadata.gov.br/Default.aspx. Acesso em: 01 dez. 2015.

Haguenauer, L. 1989. Competitividade: conceitos e medidas. Uma resenha da bibliografia recente com ênfase no caso brasileiro. UFRJ, Instituto de Economia Industrial, Rio de Janeiro, RJ, Brasil.

Hermida, C.C.C; Xavier, C.L. 2012. Competitividade na Indústria Brasileira no período recente: desempenho de categorias selecionadas a partir da taxonomia de Pavitt. Revista Nacional de Inovação, 11(2): 365 - 396.

Instituto Brasileiro de Geografia e Estatística [IBGE]. 2016. Produção Animal no $2^{\circ}$ trimestre de 2014. 2015. Disponível em: <http://ibge.gov.br/home/estatistica/indicadores/ agropecuaria/producaoagropecuaria/abate-leite-couroovos_201402comentarios.pdf>. Acesso em 22 abr. 2016.

Zucchi, J.D. 2010. Panorama dos principais elos da cadeia agroindustrial da carne bovina brasileira. Informações Econômicas, 40(1): 18-33.

Machado, L.V.N; Amin, M.M. 2005. Análise da Posição Competitiva do Brasil no Mercado Internacional de Carne Bovina: Uma Aplicação do Método de Constant-MarketShare (CMS) In: XLIII Congresso da Sociedade Brasileira de Economia e Sociologia Rural, 2005, Ribeirão Preto. Anais do XLIII Congresso da Sociedade Brasileira de Economia e Sociologia Rural.

Macedo, L.; Lima, L.C. de O. 2011. Oligopólio Mundial, Investimento Estratégico e Arena Competitiva: O Caso da Indústria Frigorífica de carne Bovina. In: VIII Simpósio de Excelência em Gestão e Tecnologia, 2011, Rezende - RJ. Anais do VIII Simpósio de Excelência em Gestão e Tecnologia. p. 1-15.

Melz,, L.J.; Marion Filho, P.J.; Bender Filho, R.; Gastardelo, T.A.R. 2014. Determinantes da demanda internacional de carne bovina brasileira: evidências de quebras estruturais. Revista de Economia e Sociologia Rural, 52(4):743760 .

Ministério da Agricultura Pecuária e Abastecimento [MAPA]. 2015. Disponível em: <http://www.agricultura.gov.br/>. Acesso em 01 jun. 2016.

Ministério do Desenvolvimento, Indústria e Comércio Exterior [MDIC]. 2014. Disponível em: <http:// www.desenvolvimento.gov.br//sitio/interna/interna. php?area $=5 \&$ menu $=4958 \& \mathrm{refr}=1161>$. Acesso em: 12 maio 2015.

Ministério do Desenvolvimento, Indústria e Comércio Exterior. Secretaria de Comércio Exterior. 2019. Barreiras Comerciais. 
Disponível em: http:/ /www.mdic.gov.br/comercio-exterior/ negociacoes-internacionais/803-barreiras-comerciais. Acesso em: 20 fev. 2019.

Miranda, S.H.G. Cunha Filho, J.H.; Burnquist, H.L.; Barros, G.S.A.C. 2004. Normas Sanitárias e Fitossanitárias: Proteção ou Protecionismo. Informações Econômicas, 34(2):2535 .

Marfrig Group. 2008. Relatórios anuais. Disponível em: <http://www.marfrig.com.br/pt/sustentabilidade/ relatorios-anuais>. Acesso em: 20 dez. 2018.

Rubin, L.S., A.daS. Ilha. 2008. O comércio potencial brasileiro de carne bovina no contexto de integração regional. Revista de Economia e Sociologia Rural, 46(4): 1067-1093. Disponível em: <http://www.scielo.br/scielo. php? script $=$ sci_arttext\&pid $=$ S0103-20032008000400007. Acesso em: 03 jun. 2016.

Sanguinet, E.R., Lorenzoni, R.K., Pelegrini, T., Dorr, A.C., Fruet, A.P,B., Klinger, A.C.K. 2013.. Mercado Internacional de Carne Bovina Brasileira: Uma Análise dos Índices de Concentração das Exportações de 2000 a 2011. Revista Eletrônica em Gestão, Educação e Tecnologia Ambiental.11(11): 2389-2398.

Schwantes, F., Campos, A.C., Lírio, V.S. 2012. Efeitos das barreiras geográficas e comerciais sobre as exportações brasileiras de carne bovina (1996-2007). Revista Teoria e Evidência Econômica, 18(38). Disponível em: < http://www. upf.edu.br/seer/index.php/rtee/article/view/3427/2265>. Acesso em: 04 jun. 2016.

Silva, F.N., Malardo, M., Cecherini, G., Montebello, A.E.S., Marjota-Maistro, M.C. 2014. Desempenho Internacional do Agronegócio Brasileiro 1990 a 2012. Revista Científica da Unar. 8(1): 1-11. Disponível em: <http://revistaunar.com. br/cientifica/documentos/vol8_n1_2014/9_desempenho_ internacional_agronegocio_brasileiro.pdf>. Acesso em: 21 abr. 2016.

Silva, S.Z., Triches, D., Malafaia, G. 2011. Análise das barreiras não tarifárias à exportação na cadeia da carne bovina brasileira. Revista de Política Agrícola. 20(2): 23-39. Disponível em: <file:///C:/Users/jessi/Downloads/57-180-1-SM.pdf>. Acesso em: 06 jun. 2016.

Tirado, G., Costa, S.J., Carvalho, J.M., Thomé, K.M. 2008. Cadeia Produtiva da carne bovina no Brasil: Um estudo dos principais fatores que influenciam as exportações. In: XLVI Sociedade Brasileira de Economia, Administração e Sociologia Rural, 2008, Rio Branco. Disponível em: <http:// sober.org.br/palestra/9/468.pdf>. Acesso em: 22 abr. 2016.

Zucchi, J.D.; Caixeta Filho, J.V. 2010. Panorama dos Principais Elos da Cadeia Agroindustrial da Carne Bovina Brasileira. Informações Econômicas (Impresso), 40: 18-33.

Waquil, P.D.; Alvim, A.M. 2006. Acordos comerciais e o setor produtivo de carne bovina: estimativas de ganhos para o Mercosul. Revista de Economia e Agronegócio, 4(2):171194. 